\title{
Fibromyxoma of the Lateral Skull Base in a Child: Case Report
}

\author{
Paul Klimo, Jr. 1,2,3,4 Tushar Jha ${ }^{5}$ Asim F. Choudhri ${ }^{2,3,6}$ \\ ${ }^{1}$ Murphey Neurologic \& Spine Institute, Semmes, Memphis, \\ Tennessee, United States \\ ${ }^{2}$ Le Bonheur Children's Hospital, Memphis, Tennessee, United States \\ 3 Department of Neurosurgery, University of Tennessee Health \\ Science Center, Memphis, Tennessee, United States \\ ${ }^{4}$ St. Jude Children's Research Hospital, Memphis, Tennessee, \\ United States \\ ${ }^{5}$ Department of Neurosurgery, Georgetown University, Washington, \\ District of Columbia, United States \\ 6 Department of Radiology, University of Tennessee Health Science \\ Center, Memphis, Tennessee, United States \\ ${ }^{7}$ Department of Pathology, University of Tennessee Health Science \\ Center, Memphis, Tennessee, United States
}

Royce Joyner ${ }^{2,7}$

L. Madison Michael II 1,3

\author{
Address for correspondence Paul Klimo, Jr., MD, MPH, Murphey \\ Neurologic \& Spine Institute, Semmes, 6325 Humphreys Blvd., Memphis, \\ TN 38120, United States (e-mail: pklimo@semmes-murphey.com).
}

J Neurol Surg Rep 2013;74:105-110.

\begin{abstract}
Keywords

- fibromyxoma

- myxoma

- child

- pediatric

- skull base

- petrous

- mesenchymal

- tumor

- benign

Purpose Fibromyxomas and myxomas are benign tumors of mesenchymal origin usually found outside the nervous system, most commonly in the atrium of the heart. They can also arise in the mandible or maxilla, but it is exceedingly rare to find them within the skull base. The history, histologic features, and the literature, with emphasis on other pediatric cases, are reviewed for this uncommon skull base neoplasm.

Methods We describe the case of a 13-year-old girl who presented with a 1-year history of facial weakness, numbness, and hearing loss. A large locally destructive tumor centered in the petrous bone was found on magnetic resonance imaging.

Results A mastoidectomy combined with a middle fossa craniotomy was performed for gross total resection. The child is disease free 12 months after surgery.

Conclusion Diagnosis could not be made solely on radiographic studies because of the lack of pathognomonic imaging features. Radical resection provided the patient the best chance of cure. Long-term surveillance is necessary to monitor for tumor recurrence.
\end{abstract}

\section{Introduction}

A diverse collection of nonneoplastic and neoplastic processes can involve the lateral skull base (i.e., temporal bone). ${ }^{1}$ The latter includes a group of tumors of mesenchymal origin; the most common are chordomas and chondrosarcomas. Other mesenchymal tumors that share some common featuressuch as chondromas and chondromyxoid fibromas-can also occur in this location, although it is exceedingly rare to find them in the skull base, as exemplified by the small number of case reports in the literature, and even more unusual in children. ${ }^{2-7}$ They are more commonly found in sites outside of the neuraxis, such as the trunk, extremities, long bones, and jaw. They are most often painless, benign, and slow growing, but they are locally destructive with expansion of the surrounding bony cortices. Surgery is the primary means of treatment.

Fibromyxoma is another such tumor. These lesions tend to occur in the mandible rather than the skull and are received

January 15, 2013

accepted after revision

June 14, 2013

published online

July 30, 2013
DOI http://dx.doi.org/

10.1055/s-0033-1351115. ISSN 2193-6358. (c) 2013 Georg Thieme Verlag KG
Stuttgart · New York

License terms

(1) $\Theta \circledast$ 
histologically benign but progressively expansile. ${ }^{8,9}$ We report a case of a child with a fibromyxoma originating within the temporal bone. With this case, we hope to educate the reader on the presentation, imaging characteristics, and treatment of this atypical tumor and review the pediatric cases in the literature to date.

\section{Case Report}

\section{History and Examination}

A 13-year-old black girl, with known sickle cell anemia (HbSS), presented to the emergency department with a 1week history of headaches and a 1-year history of right facial weakness and numbness. The child's mother had noticed a difference in her smile compared with past photographs. Findings on neurologic examination included a mild but noticeable peripheral facial weakness with preserved ability to completely close the eye (House-Brackmann grade III/VI). The Weber test lateralized to the left, and the Rinne test demonstrated bone conduction greater than air conduction on the right, thus showing combined conductive and sensorineural hearing loss on the right side. There was hypesthesia of the right V2 and V3 dermatomes. The patient had no longtract signs and no pathologic reflexes.

\section{Imaging}

Given the child's history of HbSS and her neurologic deficit, magnetic resonance imaging (MRI) was performed to exclude an infarction or a mass. MRI revealed a mixed solid and cystic mass measuring $8.6 \times 4.1 \times 3.8 \mathrm{~cm}$ with nearcomplete replacement of the right petrous temporal bone and clivus (-Fig. 1). The lesion was predominantly hyperintense on T2-weighted imaging (-Fig. 1A). The lesion was hypointense on T1-weighted imaging (-Fig. 1B), with linear internal areas of enhancement (-Fig. 1C), without any focal nodularity. There were no internal areas of abnormal diffusion restriction (-Fig. 1D). The T2 hyperintense areas did not demonstrate enhancement and had incomplete suppression on fluid-attenuated inversion recovery sequences, suggesting proteinaceous fluid or myxoid matrix. A computed tomography (CT) scan was then obtained to evaluate osseous integrity (-Fig. 2 ). The mass resulted in thinning of the expanded cortical margins, with preservation of the otic capsule and ossicles. There was demineralization of the petrous apex and clivus, and the lesion showed no internal calcified matrix. CT showed a narrow zone of transition at the margins of the lesion, and CT and MR showed the lesion was well circumscribed. CT showed demineralization of the margins of the carotid canal, and although there was slight narrowing of the petrous segment of the right internal carotid artery, it remained patent.

The lesion had caused cephalad displacement of the pituitary gland (-Fig. 1B); however, there was no evidence of pituitary invasion or of any other brain parenchyma. Additionally, the mass caused effacement of the right cerebellopontine angle cistern, flattening of the right ventral pons, uplifting of the cisternal segment of the right trigeminal nerve, posterior rotation of the right internal auditory canal, and resulting stretching of the cisternal segments of the ipsilateral cranial nerves VII and VII. The circumscribed mass filled the tympanic cavity and caused inward bowing of the sigmoid plate with resulting effacement of the right sigmoid sinus.

Although there is a broad differential, careful attention to imaging characteristics can help stratify the list. ${ }^{10}$ A petrous apex cholesteatoma/epidermoid should demonstrate diffusion restriction, and a cholesterol granuloma typically has hyperintense T1 signal and should not have enhancing soft tissue. Aneurysmal bone cysts and giant cell tumors most often have internal fluid levels from prior hemorrhage. Fibrous dysplasia can have dominant cystic components but typically has more solid osseous findings than in this case. Chondromas have internal areas of calcification and more aggressive margins, unlike the circumscribed margins seen in this case. ${ }^{11} \mathrm{~A}$ giant intraosseous aneurysm of the petrous segment of the internal carotid artery can result in an expansile mass; however, the internal carotid artery appeared to be distinct in this case, and linear areas of enhancement would not be expected within an aneurysm. The leading prospective imaging differential in this case was an expansile lesion with a myxoid matrix and fibrous contents, such as a
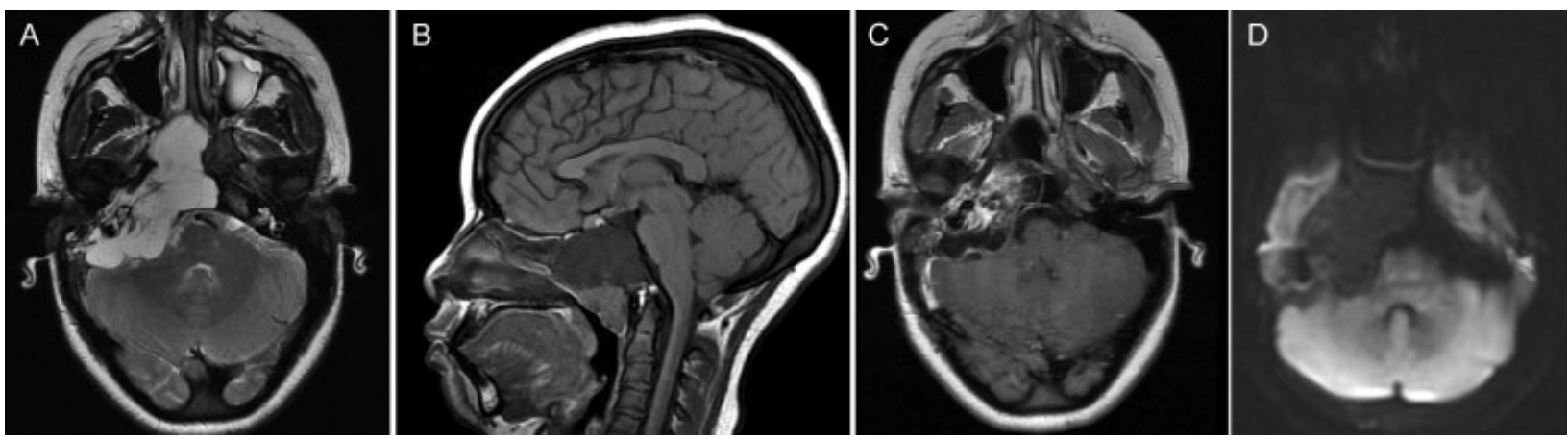

Fig. 1 (A) Axial T2-weighted magnetic resonance imaging through the skull base shows an expansile T2 hyperintense mass centered in the right petrous apex with linear internal hypointense septations. (B) Sagittal T1-weighted imaging shows that the mass involved the clivus and was predominantly T1 hypointense. (C) Axial T1-weighted image taken after gadolinium administration shows central areas of enhancement of internal septations. (D) Diffusion-weighted imaging shows no evidence of diffusion restriction. 

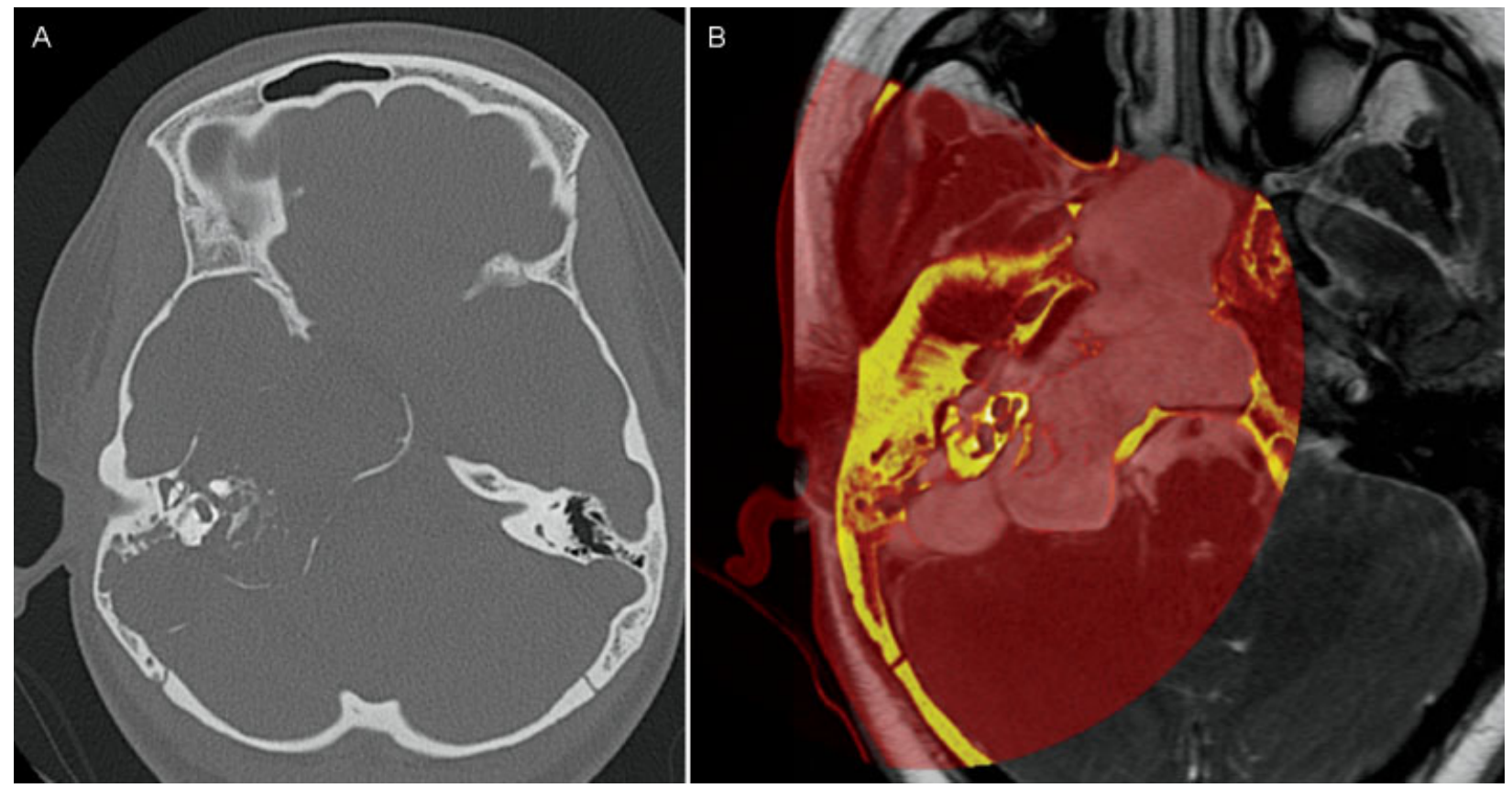

Fig. 2 (A) Axial bone algorithm computed tomography (CT) showing the intraosseous lesion was expansile and resulted in cortical thinning but without discrete erosion. (B) Fusion image combining CT (orange) with axial T2-weighted image shows sparing of the otic capsule and ossicles.

chondromyxoid fibroma, fibromyxoma, or other related lesion.

\section{Operation}

We planned a combined middle fossa/transtemporal approach to the tumor. A standard retroauricular C-shaped incision was performed. It began $3 \mathrm{~cm}$ superior to the pinna of the right ear and was carried inferiorly and posteriorly to end in a preexisting skin crease. A musculoperiosteal flap was developed and mobilized inferiorly in preparation for closure of the wound at the end of the case. At this point, the otolaryngology team started drilling the mastoid bone. Immediately upon removal of the outer cortex of the mastoid, tumor was encountered. Grossly, it was gray, had a gelatinous consistency, and was hypovascular. These characteristics facilitated removal and required sparse drilling. The neoplasm appeared to replace the cancellous portion of the temporal bone because all cortical margins, such as the internal auditory canal and the Fallopian canal, were preserved. A right middle fossa craniotomy was performed to enhance exposure of the petrous apex region and for visualization of the petrous carotid artery. The greater superficial petrosal nerve and mandibular division of cranial nerve $\mathrm{V}$ were identified. In addition, the middle meningeal artery was cauterized and transected. An anterior petrosectomy followed. Tumor discovered immediately posterior to the genu and horizontal portion of the carotid artery was removed. The last remnant of tumor taken out was the portion inferior to the sella turcica and protruding into the sphenoid sinus. No cerebrospinal fluid was seen during surgery. Frameless neuronavigation and a 30-degree endoscope were used to confirm that all viable tumor was removed. Subcutaneous fat and fascia lata were harvested from the right thigh. The otolaryn- gology team then returned to pack the eustachian tube. Fat, fascia lata, and the vascularized musculoperiosteal flap were used to obliterate the large cavity created by the lesion. The wound was closed in a multilayered fashion.

\section{Histopathologic Examination}

The tumor was a uniform benign spindle cell neoplasm consistent with a fibromyxoma (-Fig. 3). Immunohistochemistry revealed cells reactive for S-100 and actin but negative for CD-34, desmin, myogenin, cytokeratin AE1/AE3, and epithelial membrane antigen. There was no increased mitotic activity.

\section{Postoperative Course}

The immediate postoperative MRI did not suggest residual tumor. Not unexpectedly, the patient did have slight worsening of her VII nerve function after surgery. She was discharged on postoperative day 6 . Two months after surgery, she had a gold weight placed in her upper eyelid to correct her lagophthalmos and correction of her lower lid paralytic ectropion. Almost 11 months after surgery, she had a bone-anchored hearing aid placed. Twenty-four months after surgery, she has regained some facial nerve function back to her preoperative grade (III/VI) and has no evidence of recurrent disease (-Fig. 4).

\section{Discussion}

Fibromyxoma, which we consider for practical purposes to be synonymous with myxoma, is a very rare mesodermalderived neoplasm that may occur in any part of the skull base but has its origin in sutures, such as the sphenopetrosal or petrooccipital. In 1871, Virchow ${ }^{12}$ first used the term 


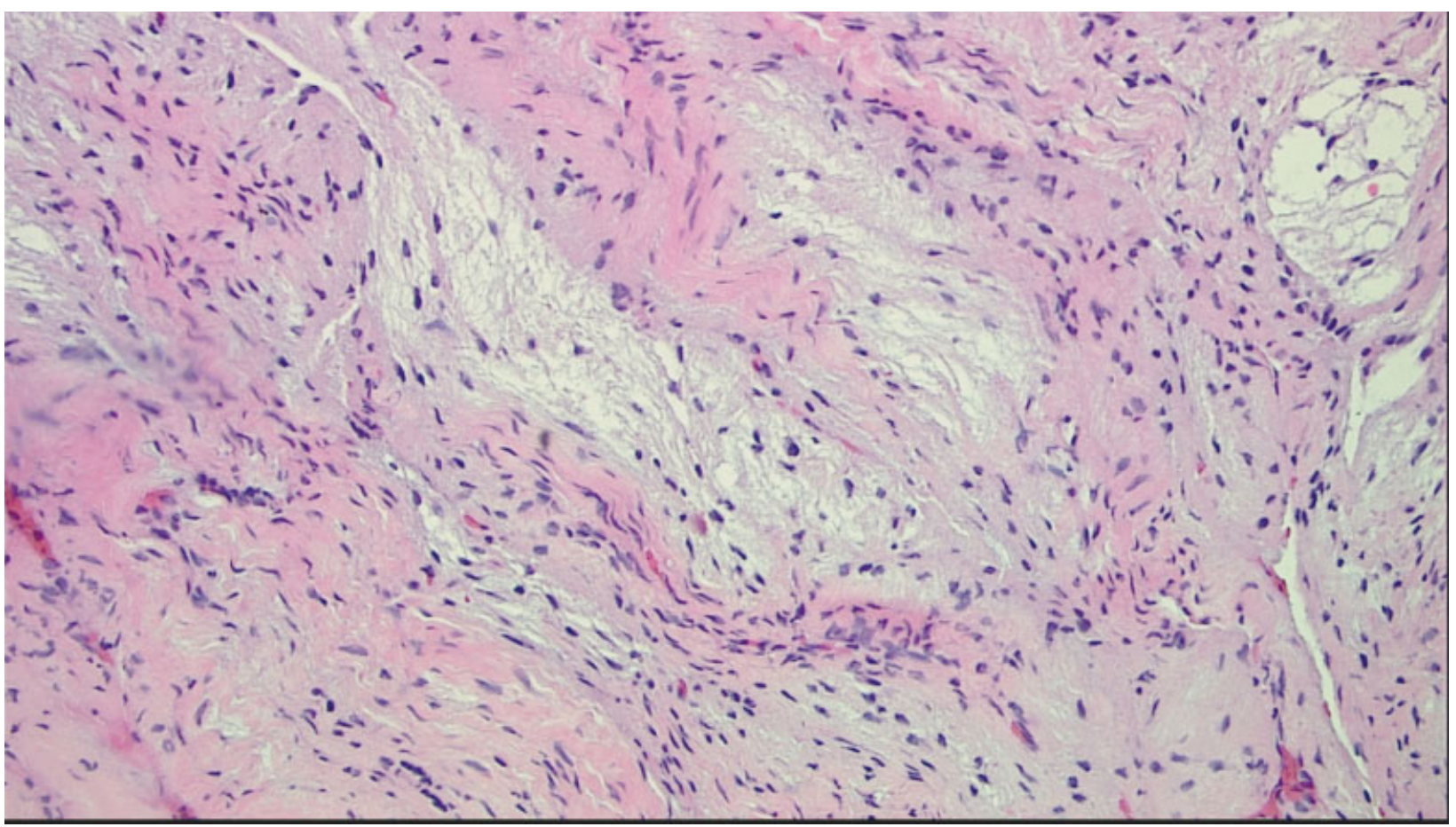

Fig. 3 Histopathologic specimen showing fibromyxoma (hematoxylin and eosin). Note the alternating dense fibroconnective tissue and relatively hypocellular foci with myxoid matrix and spindle cells.

myxoma to describe tumors resembling the mucinous tissue of the umbilical cord. In 1948 , Stout ${ }^{13}$ provided the pathologic definition of a myxoma that persists to this day: fusiform and stellate cells embedded in a pulpy mucoid stroma lacking chondroblast, lipoblast, striated muscle, and other differentiated cells with few tumor vessels and monocentric orientation. Fibromyxomas were first reported by Marcove et al $^{14}$ in 1964 in three patients with extracranial skeletal tumors. These neoplasms have higher amounts of fibroblasts, myofibroblasts, collagen fibers, and vessels than

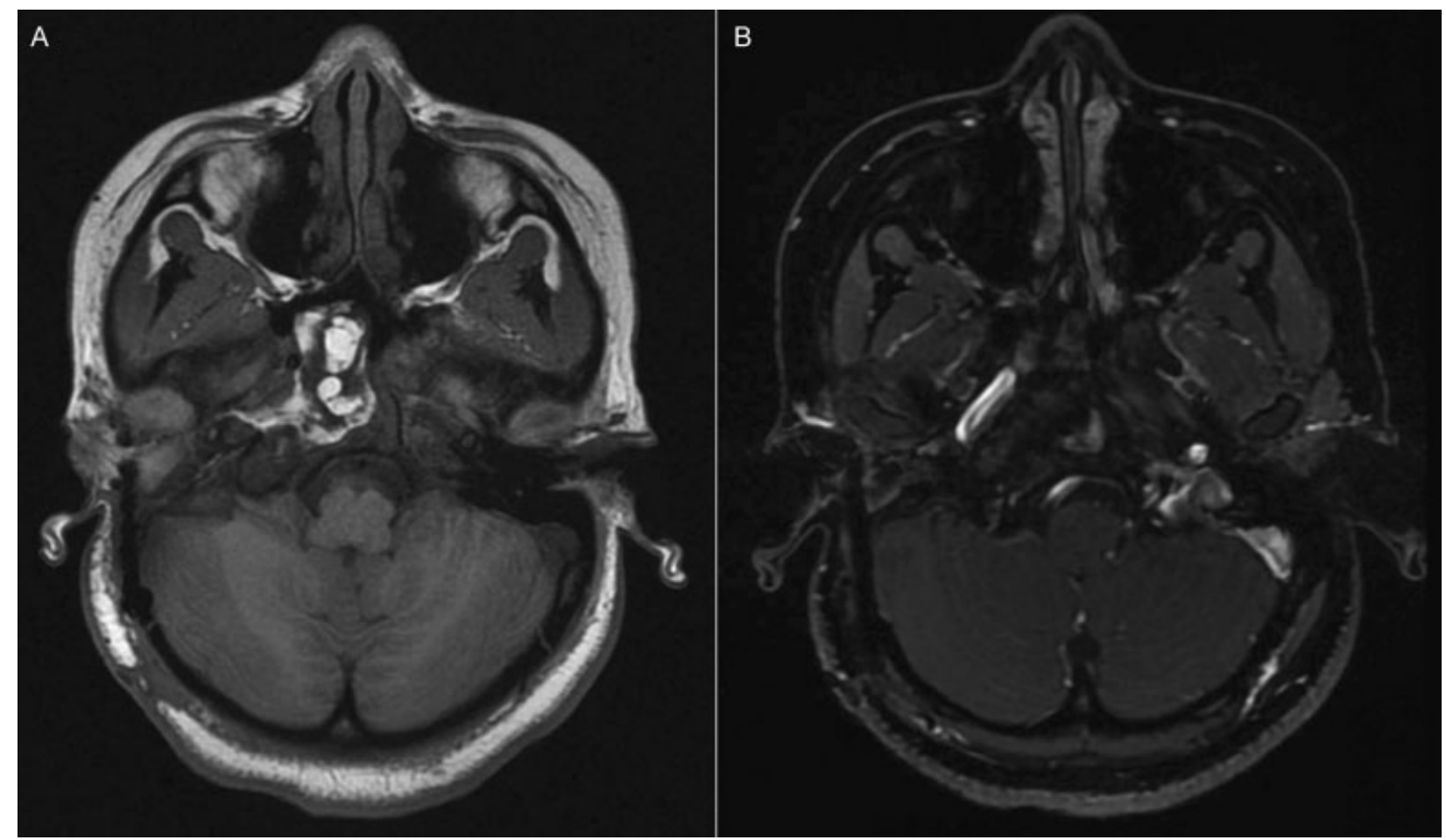

Fig. 4 (A) Axial T1-weighted magnetic resonance (MR) image shows hyperintense signal in the resection cavity corresponding to fat packing. (B) Axial T1-weighted postgadolinium MR image using fat suppression shows no evidence of solid enhancing tissue within the resection cavity. 
Table 1 Pediatric ${ }^{\mathrm{a}}$ patients with fibromyxomas or myxomas described in the literature

\begin{tabular}{|c|c|c|c|c|}
\hline Study & Age $(y) /$ sex & Tumor location & Treatment & Outcome \\
\hline Ito et $\mathrm{al}^{46}$ & $11 / \mathrm{F}$ & Lateral skull base & GTR & $\mathrm{N} / \mathrm{A}$ \\
\hline Liu and Wang ${ }^{23}$ & $16 / \mathrm{M}$ & Anterior fossa & STR & "Improved" at 2 y \\
\hline Knox et $\mathrm{al}^{47}$ & $2 / \mathrm{F}$ & Lateral skull base & GTR & $\mathrm{N} / \mathrm{A}$ \\
\hline Pitkäranta et al ${ }^{24}$ & $16 / \mathrm{M}$ & Lateral skull base & GTR & No disease at $1 \mathrm{y}$ \\
\hline Srinivasan $^{6}$ & $14 / \mathrm{F}$ & Lateral skull base & GTR & No disease at $1 \mathrm{y}$ \\
\hline Osterdock et al ${ }^{5}$ & $17 / \mathrm{M}$ & Lateral skull base & GTR & $\mathrm{N} / \mathrm{A}$ \\
\hline Windfuhr et $\mathrm{al}^{26}$ & $4 / F$ & Lateral skull base & GTR & $\begin{array}{l}\text { Recurrent tumor invading eustachian tube requiring } \\
\text { resection } 1 \text { y after first surgery; no recurrence for } \\
9 \text { y thereafter }\end{array}$ \\
\hline Present case & $13 / \mathrm{F}$ & Lateral skull base & GTR & No disease at $1 \mathrm{y}$ \\
\hline
\end{tabular}

Abbreviations: GTR, gross total resection; STR, subtotal resection; N/A, not available.

aDefined as $<18$ y of age.

typical myxomas. ${ }^{15}$ Both myxomas and fibromyxomas can have areas of mature trabecular bone separated by spindle and stellate cells within a myxoid extracellular matrix, socalled ossifying myxoma.

Fibromyxomas occur much more frequently at sites distant from the central nervous system, namely the heart, subcutaneous tissue, and bone, and they usually manifest in the second to fourth decades of life. Myxomas of the head and neck occur infrequently but typically develop in the maxilla or mandible. ${ }^{16-18}$ They are characterized as gelatinous grayish white masses that replace the spongy bone and displace the cortical plates of the jaws. ${ }^{19}$ In these locations, the tumors are likely of odontogenic origin because studies have suggested that they arise from the mesenchymal tissue of the dental follicle. ${ }^{19}$ This is further supported by the tumors' resemblance to the mesenchymal portion of the tooth germ. ${ }^{19}$ Cells are immunoreactive to actin, S-100, and vimentin but not reactive to desmin or cytokeratin. ${ }^{20}$ Immunochemistry of the tumor present in our case revealed similar results. In cases in which complete resection is not possible, recurrence rates range as high as 25 to $43 \%{ }^{17,19}$

Although more rare, there are several case reports and small case series of skull base myxomas or fibromyxomas. ${ }^{4-6,21-30}$ The typical patient and histopathologic features are identical to those found in the jaws, with the tumor occurring in virtually any location in the skull base and even the posterior fossa. Radical surgery is the primary treatment and necessary to minimize the risk of recurrence. The largest series was reported by Zhang et al, ${ }^{28}$ who described 23 patients with skull base myxomas treated over a 22-year period including 14 tumors located in the parasellar area. The median age of the patients was 33 years. Subtotal resection was performed in 16 patients and total resection in 7; however, follow-up data were available in only 11 patients. Of these, four patients developed recurrence at a mean of 5.9 years. There are only a handful of pediatric cases in the literature, summarized in - Table 1. Most of the patients were in their teenage years and had tumors located in the lateral skull base. Our case represents only the eighth known published case of a fibromyxoma or myxoma in a child. The case reported by Srinivasan ${ }^{6}$ is similar to ours. That patient was a 14-year-old girl who presented with facial pain and double vision and was found to have a $3-\mathrm{cm}$ lytic expansile mass of the petrous apex. A subtotal excision was performed through an anterior extradural transpetrosal approach, but no follow-up information was provided beyond a CT performed 10 days after surgery.

Additional mesenchymal tumors can occur in the skull base and must be considered in the differential diagnosis in a young patient with insidious development of symptoms and a large locally destructive lesion. None of these tumors have pathognomonic imaging features; thus tissue procurement is key for making the correct diagnosis. Chondromyxoid fibroma is a benign cartilaginous tumor that typically arises in the metaphysis of long bones and is most similar to myxomas. There are several case reports of it arising in the temporal bone. ${ }^{3,31-34}$ Juvenile ossifying fibroma or cemento-ossifying fibroma typically arises in the paranasal sinuses, encroaches on adjacent orbital and cranial compartments, and is composed of cellular fibrous stroma, osteoid bodies, and myxomatous matrix. ${ }^{35,36}$ The histologic differential for this tumor includes fibrous dysplasia and intraosseous meningioma. Temporal bone origin has been reported. ${ }^{37-40}$ Other more rare tumors reported in the temporal bone include chondroma, ${ }^{41}$ neurothekeomas (nerve sheath myxomas), ${ }^{2}$ fibromatosis, ${ }^{42,43}$ and desmoplastic fibroma. ${ }^{44,45}$

\section{Conclusion}

Fibromyxomas and myxomas belong to a family of mesenchymal tumors that share the common characteristics of being benign, slow growing, and locally destructive. Their occurrence in the skull base is very rare and even more so in the pediatric patient. Diagnosis cannot be made solely on radiographic studies because of the lack of pathognomonic imaging features. Radical resection provides the patient the best chance of cure. Long-term surveillance is necessary to monitor for tumor recurrence. 


\section{Acknowledgment}

We thank Kristin Kraus, MSc, for reviewing and editing this manuscript.

\section{References}

1 Chapman PR, Shah R, Curé JK, Bag AK. Petrous apex lesions: pictorial review. AJR Am J Roentgenol 2011;196(3, Suppl): WS26-WS37; quiz S40-S43

2 Erdem Y, Koktekir E, Bayar MA, Yilmaz A, Caydere M. Characterization of an intracranial neurothekeoma: case report. Turk Neurosurg 2012;22(1):109-112

3 Frank E, Deruaz JP, de Tribolet N. Chondromyxoid fibroma of the petrous-sphenoid junction. Surg Neurol 1987;27(2):182-186

4 Oruckaptan HH, Sarac S, Gedikoglu G. Primary intracranial myxoma of the lateral skull base: a rare entity in clinical practice. Turk Neurosurg 2010;20(1):86-89

5 Osterdock RJ, Greene S, Mascott CR, Amedee R, Crawford BE. Primary myxoma of the temporal bone in a 17-year-old boy: case report. Neurosurgery 2001;48(4):945-947; discussion 947-948

6 Srinivasan US. Fibromyxoma of the petrous apex. Pediatr Neurosurg 2000;32(4):209-213

7 Ditta LC, Qayyum S, O'Brien TF, Choudhri AF, Wilson MW. Chondromyxoid fibroma of the orbit. Ophthal Plast Reconstr Surg 2012;28(5):e105-e106

8 Kangur TT, Dahlin DC. Myxomatous tumors of the jaws. J Oral Surg 1975;33(7):523-528

9 Abiose BO, Ajagbe HA, Thomas O. Fibromyxomas of the jawbonesa study of ten cases. Br J Oral Maxillofac Surg 1987;25(5):415-421

10 Choudhri AF, Parmar HA, Morales RE, Gandhi D. Lesions of the skull base: imaging for diagnosis and treatment. Otolaryngol Clin North Am 2012;45(6):1385-1404

11 Duan F, Qiu S, Jiang J, et al. Characteristic CT and MRI findings of intracranial chondroma. Acta Radiol 2012;53(10):1146-1154

12 Virchow R. Die Cellularpatholgie in Ihrer Begrundung auf Physiologische und Pathologische Gewebelehre. Berlin, Germany: August Hirschwald; 1871:563

13 Stout AP. Myxoma, the tumor of primitive mesenchyme. Ann Surg 1948;127(4):706-719

14 Marcove RC, Kambolis C, Bullough PG, Jaffe HL. Fibromyxoma of bone. A report of 3 cases. Cancer 1964;17:1209-1213

15 Keszler A, Dominguez FV, Giannunzio G. Myxoma in childhood: an analysis of 10 cases. J Oral Maxillofac Surg 1995;53(5):518-521

16 Canalis RF, Smith GA, Konrad HR. Myxomas of the head and neck. Arch Otolaryngol 1976;102(5):300-305

17 Aquilino R, Tuji F, Eid N, Molina O, Joo H, Neto F. Odontogenic myxoma in the maxilla: a case report and characteristics on CT and MR. Oral Oncol Extra. 2006;42:133-136

18 Andrews T, Kountakis SE, Maillard AA. Myxomas of the head and neck. Am J Otolaryngol 2000;21(3):184-189

19 Lo Muzio L, Nocini P, Favia G, Procaccini M, Mignogna MD. Odontogenic myxoma of the jaws: a clinical, radiologic, immunohistochemical, and ultrastructural study. Oral Surg Oral Med Oral Pathol Oral Radiol Endod 1996;82(4):426-433

20 Weiss S, Goldblum J. Benign soft tissue tumors and pseudotumors of uncertain type. In: Enzinger and Weiss's Soft Tissue Tumors. 5th ed. Philadelphia, PA: Mosby; 2008:1063-1092

21 DeFatta RJ, Verret DJ, Ducic Y, Carrick K. Giant myxomas of the maxillofacial skeleton and skull base. Otolaryngol Head Neck Surg 2006;134(6):931-935

22 Klein MV, Schwaighofer BW, Sobel DF, Hesselink JR. Primary myxoma of the posterior fossa. Neuroradiology 1990;32(3): $250-251$
23 Liu A, Wang CC. Primary myxomas of the skull base. J Clin Neurosci 1996;3(1):29-33

24 Pitkäranta A, Carpén O, Ramsay H. Fibromyxoma of the temporal bone. Otolaryngol Head Neck Surg 1997;117(6):S201-S203

25 Shotton JC, Kuhwoede R, Fisch U. Mesenchymal tumors of the skull base with particular reference to surgical management and outcome. Skull Base Surg 1992;2(2):112-117

26 Windfuhr JP, Schwerdtfeger FP. Myxoma of the lateral skull base: clinical features and management. Laryngoscope 2004;114(2): 249-254

27 Yin H, Cai BW, An HM, You C. Huge primary myxoma of skull base: a report of an uncommon case. Acta Neurochir (Wien) 2007; 149(7):713-717

28 Zhang L, Zhang M, Zhang J, et al. Myxoma of the cranial base. Surg Neurol 2007;68(Suppl 2):S22-S28

29 Nagatani M, Mori S, Takimoto N, et al. Primary myxoma in the pituitary fossa: case report. Neurosurgery 1987;20(2):329-331

30 Sato H, Gyo K, Tomidokoro Y, Honda N. Myxoma of the sphenoidal sinus. Otolaryngol Head Neck Surg 2004;130(3):378-380

31 LeMay DR, Sun JK, Mendel E, Hinton DR, Giannotta SL. Chondromyxoid fibroma of the temporal bone. Surg Neurol 1997;48(2): $148-152$

32 Otto BA, Jacob A, Klein MJ, Welling DB. Chondromyxoid fibroma of the temporal bone: case report and review of the literature. Ann Otol Rhinol Laryngol 2007;116(12):922-927

33 Tarhan NC, Yologlu Z, Tutar NU, Coskun M, Agildere AM, Arikan U. Chondromyxoid fibroma of the temporal bone: CT and MRI findings. Eur Radiol 2000;10(10):1678-1680

34 Thompson AL, Bharatha A, Aviv RI, et al. Chondromyxoid fibroma of the mastoid facial nerve canal mimicking a facial nerve schwannoma. Laryngoscope 2009;119(7):1380-1383

35 Lawton MT, Heiserman JE, Coons SW, Ragsdale BD, Spetzler RF. Juvenile active ossifying fibroma. Report of four cases. J Neurosurg 1997;86(2):279-285

36 Hasselblatt M, Jundt G, Greiner C, et al. Juvenile psammomatoid ossifying fibroma of the neurocranium. Report of four cases. J Neurosurg 2005;102(6):1151-1154

37 Goh EK, Cho KS, Lee IW, Chon KM. A case of isolated ossifying fibroma of the mastoid cavity of the temporal bones. Am J Otolaryngol 2006;27(5):358-361

38 O'Reilly RC, Hirsch BE, Kapadia SB. Ossifying fibroma of the temporal bone. Am J Otolaryngol 2000;21(2):131-135

39 Affleck BD, Malis DJ, Whittemore DE, Torgerson SJ. Psammomatoid ossifying fibroma of the temporal bone. Otolaryngol Head Neck Surg 2002;126(5):585-587

40 Vlachou S, Terzakis G, Doundoulakis G, Barbati C, Papazoglou G. Ossifying fibroma of the temporal bone. J Laryngol Otol 2001;115 (8):654-656

41 Xin Y, Hao S, Zhang J, et al. Microsurgical treatment of intracranial chondroma. J Clin Neurosci 2011;18(8):1064-1071

42 Jenny B, Kaye AH, Gonzales MF. Aggressive intracranial fibromatosis: case report. J Clin Neurosci 2002;9(4):450-453

43 Madnani DD, Myssiorek D, Wasserman PG, Zahtz G, Mittler M. Jugular foramen fibromatosis in a 3-month-old male. Int J Pediatr Otorhinolaryngol 2006;70(12):2119-2123

44 Dutt SN, Mirza S, Irving RM, Jones EL. Desmoplastic fibroma of the temporal bone. J Laryngol Otol 2000;114(4):314-317

45 Pensak ML, Nestok BR, Van Loveren H, Shumrick KA. Desmoplastic fibroma of the temporal bone. Am J Otol 1997;18(5):627-631

46 Ito M, Tajima A, Nitta T, Sato K, Ishii S, Ragsdale B. Massive cranial ossifying myxoma in a child. Clin Neurol Neurosurg 1990;92(3): 271-275

47 Knox GW, Roth M, Saleh H, Stiles W. A unique temporal bone lesion resembling juvenile active ossifying myxoma. Am J Otol 1996; 17(2):297-300 